\title{
Kinetic Modeling of Thrombin Induced and Collagen Induced Platelet Aggregation Pathway-A System Biology Approach
}

\author{
K M Prakash Lingam, Venugopal K R, and L M Patnaik
}

\begin{abstract}
Kinetic Modeling of a process in biochemical system has long been pursued with the aim of understanding the metabolic processes for the human system. Kinetic models that are based on elementary reactions give the best accuracy and reliability. Platelets, an important component of blood, play a major role in hemostasis, which aids in the formation of blood clots. Platelet aggregation is the clumping together of platelets in the blood. The process of converting the blood from a liquid to a solid state is called Thrombus. Platelet Aggregation is a part of the sequence of reactions leading to the formation of a Thrombus. The objective of this paper is to use kinetic modeling to study the processes of Thrombin Induced Platelet Aggregation (TIPA) and Collagen Induced Platelet Aggregation (CIPA) pathways in human system, simulate these pathways using CellDesigner and find the target drugs having antiplatelet potency.
\end{abstract}

Index Terms-Platelet aggregation, receptors, biopathways, thrombin, collagen.

\section{INTRODUCTION}

Systems biology is the study of an organism, viewed as an unified and interacting network of DNA, genes, proteins biochemical reactions and other regulatory mechanisms which give rise to life [1][2]. Simulation of biochemical systems is carried out to understand the computational processes that imitate the dynamics of the actual (biological) network. Multiple tools are usually available to perform numerical simulation of the behavior of a system described in mathematical form. Any biochemical pathway can be constructed, analyzed and simulated using these tools. Features like metabolic control analysis, flux analysis can be analyzed. These above mentioned features form the core components of system biology and are important in understanding the system structure such as gene regulatory, signaling, and biophysical and biochemical networks structures, the dynamics that includes both quantitative and qualitative analysis, the control methods of the system and design methods of the system. The relationship and interactions between various parts of a biological system including gene and protein networks involved in cell signaling can be developed using Computer simulation and

Manuscript received April 20, 2011; revised August 28, 2011

$\mathrm{K}$ M Prakash Lingam and Venugopal $\mathrm{K} \mathrm{R}$ are from University Visvesvaraya College Of Engineering Bangalore, India.

L M Patnaik is with Defence Institute of Advanced Technology, Pune, India (Tel: +91-9986629067, email: kmplingam@hotmail.com)
Mathematical models.

Blood has four components, namely Red cells, White cells, Plasma and Platelets. Platelets (thrombocytes) are small, irregularly-shaped anuclear cell fragments. Although platelets are classes as blood cells, they are actually fragments of large bone marrow cells called megakaryocytes. Blood has the ability to coagulate should one receive a cut or bruise. Platelets contain the necessary hormones and proteins for coagulation to assist in formation of blood clots. Collagen is released when the endothelial layer of a blood vessel is damaged. The Platelet binds with collagen and adheres to the blood vessel, thereby initiating the blood coagulation.

Low number of platelets leads to excessive bleeding, whereas high count of platelets may lead to stroke and other myocardial infarctions due to the formation of blood clots, which may obstruct blood vessels. Platelets stick to the injured blood vessel called as Platelet Adhesion. Platelets attach to other platelets to enlarge the forming plug, termed as Platelet Aggregation and then provide support for the process of the coagulation cascade.

The objective of kinetic modeling helps in understanding the basic reactions of platelet activation, the agonist induced platelet aggregation pathway, namely collagen and thrombin to discover which metabolite(s) should be targeted for antiplatelet drugs.

\section{BACKGROUND}

\section{A. Platelet Aggregation}

Platelet Aggregation is the clumping together of platelets in the blood. Clumping can occur in response to many different agents, including the nucleotide adenosine diphosphate(ADP), and the proteins thrombin and collagen. Platelet aggregation is a critical step in the process of clot formation to stop bleeding. Platelet aggregation is a part of the sequence of events leading to the formation of a thrombus. Blood that has been converted from a liquid to a solid state is called thrombus. The accumulation of platelets into a solid hemostatic thrombus is based on the formation of interacting multiple platelets. Platelet Platelet aggregation is mediated by integrin alpha IIb beta 3 that binds various extracellular macromolecular ligands including Fibrinogen and Von Willebrand Factor $(v W F)$.

The dimeric structure of fibrinogen and the multimeric structure of $v W F$ allow these ligands to adhere with platelets, thereby clumping platelets to generate platelet aggregation [4]. In inactivated resting platelets, alpha IIb beta 3 is in an 
off state, in which ligand binding affinities are low and no signaling occurs. Platelet activation induces intracellular signaling processes that influence the cytoplasmic part of alpha IIb beta 3, rapidly converting alpha IIb beta 3 into an active conformation (inside-out signaling), which results in Fibrinogen $/ v W F$-mediated platelet aggregation.

There are many factors involved in the formation of blood clots. When blood vessel wall gets damaged due to an injury, platelets get activated. Activated Platelets gather at the site of an injury and clump to form a plug or aggregate that helps to limit the flow of blood and promote healing. Platelet activation and coagulation do not occur inside an intact blood vessel. Platelet-plug formation is initiated by the adherence of platelets to subendothelial collagen, which commences the coagulation process.

\section{B. Agonist}

An agonist is a chemical that binds and activate a receptor displaying full efficency (therapeutic effect) at that receptor of a cell and triggers a response by that cell. Whereas an agonist causes an action, an antagonist blocks the action of the agonist at a receptor molecule, inhibiting the signal produced by the receptor-agonist coupling. Strong agonists are those which produce reaction with its binding, whereas the weak agonist does not produce the reaction like the strong ones but in higher concentration they tend to produce the effect produced by the strong agonists. Table 2.1 shows the agonists involved in platelet aggregation.

\section{Hemostasis}

The process of blood clotting and then the subsequent dissolution of the clot following the repair of the injured tissue are termed as hemostasis. It is composed of four major events that occur in a set order following the loss of vascular integrity. The initial step of the process is vascular constriction. This helps in limiting the flow of blood to the area of injury. Platelets become activated by thrombin and aggregate at the injury site forming loose platelet plug. The protein fibrinogen is responsible for platelet clumping. The platelets clump by binding to collagen that becomes exposed following the rupture of the endothelial lining of vessels. Upon activation platelets release ADP and Thromboxane, Serotonin, Phospholipids.

TABLE 2.1: AgONISTS IN Platelet AgGREgAtion

TABLE 2.1: AGONISTS IN PLATELET AGGREGATION
\begin{tabular}{|c|c|}
\hline Agonist & Type \\
\hline Thrombin & Strong \\
\hline Collagen & Strong \\
\hline Thromboxane & Weak \\
\hline 1,2-dioctanoylglycerol & Weak \\
\hline ADP & Weak \\
\hline Epinephrine & Weak \\
\hline Adrenaline & Weak \\
\hline $\begin{array}{c}\text { Phorbol-12Myristate-13 Acetate } \\
\text { (PMA) }\end{array}$ & Strong \\
\hline Arachidonic acid & Weak \\
\hline Platelet activating factor & Strong \\
\hline
\end{tabular}

Lipoproteins and other proteins important for the coagulation cascade. The activated platelets change their shape to accommodate the formation of the plug. To make the initially loose platelet plug stable, a fibrin mesh forms and entraps the plug. If the plug contains only platelets it is called as white thrombus. Otherwise, it is called as red thrombus. Finally, the clot must be dissolved in order for normal blood flow to resume following tissue repair. This dissolution of clot occurs by the action of plasmin.

\section{Metabolite Notations}

The metabolite notations that are used in the flux map of thrombin induced and collagen induced platelet aggregations are shown below in Table 2.2.

\section{RELATED WORK}

TABLE 2.2: Platelet AgGRegation Pathway Metabolite Notations

\begin{tabular}{|c|l|l|}
\hline S.No & Metabolite & Notation \\
\hline 1. & GP6 & Glycoprotein VI \\
\hline 2. & GP2b3a & Glycoprotein 2 -beta 3-alpha \\
\hline 3. & Gq & $\begin{array}{l}\text { Guanine nucleotide-binding } \\
\text { protein q-Calcium Ion Signal-ling }\end{array}$ \\
\hline 4. & GDP & Guanine DiPhosphate \\
\hline 5. & GTP & Guanine DiPhosphate \\
\hline 6. & PLC & Phospholipase C \\
\hline 7. & PAR & Protease Activated Receptor \\
\hline 8. & ERK & $\begin{array}{l}\text { Extracellular } \\
\text { Kinase }\end{array}$ \\
\hline 9. & MAP & Mitogen Activated Protein \\
\hline 10. & MEK & Map kinase/Erk Kinase \\
\hline 11. & PIP3 & $\begin{array}{l}\text { PhosphatidylInositol-trisPhosphat } \\
\text { e }\end{array}$ \\
\hline 12. & PIP2 & $\begin{array}{l}\text { PhosphatidylInositol } \\
- \text { bisPhosphate }\end{array}$ \\
\hline 13. & IP3 & InositoltrisPhosphate \\
\hline 14. & DAG & DiAcylGlycerol \\
\hline 15. & PKC & Protein Kinase C \\
\hline 16. & PI3K & Phospholnositide 3 Kinase \\
\hline 17. & LAT & Linker for Activation of T-cells \\
\hline 18. & ER & Endoplasmic Reticulum \\
\hline 19. & Ca-ion & Calcium channel in ER \\
\hline 20. & Ca_c1 & $\begin{array}{l}\text { Calcium concentration in } \\
\text { Compartment 1(Platelet Cell) }\end{array}$ \\
\hline 21. & Ca_c2 & $\begin{array}{l}\text { Calcium concentration in } \\
\text { Compartment 1(ER) }\end{array}$ \\
\hline & & \\
\hline
\end{tabular}

Thrombin cleaves $G p V$ and interacts with $G p I b \alpha$ from the GpIb-IX-V complex[5]. The lack of $G p V$ in mice enhances platelet responses to thrombin and interestingly these platelets react strongly to inactivated-thrombin downstream of GpIb $\alpha[6]$. Thrombin-GpIb $\alpha$ also facilitates thrombin cleavage of $P A R-1$. Signals generated by $P A R-1$ and $P A R-4$ are similar since both receptors couple $G q$ and $G 12 / G 13$ family members of heterotrimeric G-proteins [4]. PARs also couple to G12/G13 family members, which activate members of the Rho family kinases. Activated Rho signals platelet shape change and secretion by upregulating the phosphorylation of myosin light chain [7]. G12/13 proteins interact with several other proteins like Bruton's tyrosine kinase(Btk), RASGTPase activating protein, suggesting that through these interactions G12/13 proteins are able to mediate several intracellular responses. PAR- 1 uses the Hir motif in a dock and lock mechanism to overcome the entropic 
and kinetic barriers leading to formation of productive PAR-1-thrombin complexes. The dock and lock mechanism describes the two-step binding of PAR-1 to thrombin [8]. $\mathrm{X}$-ray crystallographic and kinetic studies showed that thrombin interacts with the $P A R-1$ exodomain substrate at two distant and distinct sites, both of which play essential roles in the overall cleavage reaction.

Activation of three different types of PI3Ks in thrombinstimulated platelets occurs. Zhang et al., in [9] reported that $P I 3 K-I A$ activation is downstream of Rho, which coimmunoprecipitates with the p85 subunit, although no direct association between Rho and PI3K-IA has been found. A role for tyrosine phosphorylated proteins in the activation of $P I 3 K-I A$ has been suggested in [9] but the identity of those proteins remain unknown.

Masaaki et al., in [10] have proposed to portray the mechanism through which platelets adhere to the immobilized $v W F$ under flow condition. One is $v W F$ may undergo a conformational change after immobilization on the surface to enhance its binding affinity to platelets and the other one is immobilization of $v W F$ may itself increase the affinity to platelets because $v W F$ is a multimeric protein with very high molecular weight. Collagen binding results in GP VI clustering and tyrosine phosphorylation of the FcReceptor $\gamma$-chain $(F c R \gamma)$ by the Src family kinases Lyn and Fyn [11]. This results in the binding of the tyrosine kinase $S y k$, which becomes tyrosine phosphorylated and activated. This leads to the tyrosine phosphorylation of the transmembrane adaptor protein Linker Activation of T-cells $(L A T)$, which function to assemble a complex of signaling proteins.

\section{Thrombin Induced Platelet AgGREGAtion}

Thrombin is a trypsin-like serine protease that regulates several physiological responses in the vascular system, including the cleavage of fibrinogen to generate insoluble fibrin for a clot. Thrombin also regulates cellular activities mainly by the cleavage of a family of receptors termed Protease-Activated Receptors (PARs). Prothrombin, the precursor of thrombin, circulates freely in plasma at concentrations around $100 \mu \mathrm{g} / \mathrm{ml}$. In order for Prothrombin to be converted to thrombin the activation of certain coagulation factors such as factor $V, V I I$ and $X$ is required. These activated factors form complexes on the membranes of activated platelets expressing positively charged Phospholipids (mainly phosphatidylserine) and in the presence of $\mathrm{Ca}^{2+}$, activated factors $\mathrm{Va}$ and $\mathrm{Xa}$ convert prothrombin into thrombin [12].

For many years, it was known that thrombin caused platelet aggregation, but the receptor(s) responsible for this remained elusive. In the beginning of the 1990's, a receptor with the particularity that upon cleavage of its $\mathrm{N}$-terminal extracellular domain was able to interact with itself through its newly exposed $\mathrm{N}$-terminal was described and a new family of receptors was created: protease-activated receptors $(P A R s)$. The first receptor identified was termed PAR-1 and was immediately identified as the receptor responsible for thrombin-induced responses in platelets, but soon it became clear that platelets could be also expressed through other Thrombin receptor(s), namely PAR-3 and PAR-4. While the roles of $P A R-1$ and $P A R-4$ in mediating platelet responses are established; PAR-3 expression in human platelets is minimal and its contribution to platelet responses uncertain. In platelets, besides cleaving PARs, thrombin also cleaves $G p V$ and interacts with $G p I b \alpha$, both members of the GpIb-IX-V complex.

Calcium release induced by $P A R s$ activates $P K C$, modulating integrin alpha IIB beta 3 and opening integrin ligand binding sites to contribute to platelet aggregation.

Thrombin cleaves $G p V$ from the $G p I b-I X-V$ Complex. The lack of $G p V$ in mice enhances platelet responses to thrombin and interestingly these platelets react strongly to inactivated-thrombin downstream of GpIba [6]. Finally Thrombin- GpIbo interaction also facilitates thrombin cleavage of $P A R-1$. Platelet activation and aggregation are mediated by thrombin cleavage of the $P A R-1$ receptor. The specificity of thrombin for $P A R-1$ is enhanced by binding to a Hirudin-like region (Hir) located in the exodomain of the receptor. $P A R-1$ plays an important role in platelet activation and blood coagulation: $P A R-1$ and $P A R-4$ mediate platelet aggregation in humans. $P A R-1$ is the predominant thrombin receptor mediating human platelet function.

$P A R-1$ is cleaved by picomolar concentrations of thrombin; in contrast, $P A R-4$ cleavage requires 10 to 100 -fold higher concentrations. The difference in sensitivity is due to a hiruddin-like domain present in the exodomain of PAR-1 (and $P A R-3$ ) but not in $P A R-4$. This sequence facilitates an interaction with thrombin that enhances the receptor cleavage. Another important difference between these two receptors is that cleaved $P A R-1$ is rapidly shutoff by phosphorylation, after which, it is internalized and directed to lysosomes where it is mostly degraded [13]. In contrast, cleaved PAR-4 is down-regulated much more slowly and therefore generates long-lasting signals. Furthermore, signals generated by $P A R-4$ seem to be more robust than those ones generated by $P A R-1$. Proteinase-activated receptors are a recently described, novel family of seven transmembrane G-protein-coupled receptors [14]. PAR-1 mediates human platelet activation at low thrombin concentrations, whereas $P A R-4$ contributes to thrombin-induced platelet only at high thrombin concentrations. PARs are G Protein-Coupled Receptors $(G P C R)$ that utilizes an intriguing mechanism to convert an extracellular proteolytic cleavage event into $a$ Transmembrane signal: these receptors carry their own ligands, which remain silent until activated by receptor cleavage. The activation of $P A R$-induced platelet aggregation is inhibited by aspirin, indicating that Thromboxane production induced by $P A R$ signalingcontributes to platelet aggregation.

\section{A. Pathway Description}

The flux map, created in CellDesigner 6.0.1, used in the simulation of Thrombin Induced PlateletAggregation (TIPA) pathway is shown in Fig. 4.1[15][16][17]. Platelet activation and aggregation are mediated by thrombin cleavage of the exodomain of the $P A R-1$ receptor [18]. The specificity of thrombin for $P A R-1$ is enhanced by binding to a Hirudin-like region (Hir) located in the exodomain of the receptor. $R A S$ is a small GTPase protein, which is active in the $G T P$-bound state. $R A S$ is a 
GTPase protein, which is activated following conversion from a $G D P$ to $G T P$-bound state. $R A S$ and all of the components of the $R A S \pm E R K$ signaling pathway ( $R A S, R A F$, and $M E K)$ are expressed in platelets and undergo activation. $R A F$ activates $M E K 1$ and $M E K 2$, the dual-specificity protein kinases that directly phosphorylate and activate ERKI (Extracellular signal-Regulated Kinase) and ERK2. RAF regulates the kinases $M E K$ (Map/Erk Kinase) which in turn activates $E R K 1-2$, which regulates a number of transcription factors, cytoplasmic proteins and 1-stream kinases. PhosphoLipase C $(P L C)$ catalyzes the hydrolysis of PhosphatidylInositol 4, 5-Bisphosphate (PIP2) to Inositol 1, 4, 5-Trisphosphate (IP3) and DiAcylGlycerol $(D A G)$. These molecules regulate the mobilization of intracellular $\mathrm{Ca}^{2+}$ and Protein Kinase

$\mathrm{C}(P K C)$ activation, respectively. PLC activation leads to generation of IP3 which helps in mobilizing intracellular calcium from the endoplasmic reticulum to cytosol. Activation of $P L C$ results in phosphoinositide hydrolysis, $\mathrm{Ca}^{2+}$ mobilization $D A G$ formation, and $P K C$ activation. Once a signal molecule binds to a receptor, the enzyme $P L C$ is activated. This enzyme cleaves the plasmamembrane phospholipids PIP2 into two other second messengers, DAG and IP3. IP3, a small molecule, quickly diffuses through the cytosol and binds to a ligand-gated Calcium channel in the ER membrane, causing it to open. Calcium ions flow out of the ER (down their gradient, from areas of higher to lower concentration), raising the $\mathrm{Ca}^{2+}$ level in the cytosol. For complete platelet aggregation, the plasma membrane integrin $\alpha_{l l b} \beta_{3}$ has to be activated and bind with fibrinogen.

\section{B. Kinetic Parameters}

Table 4.1 shows the kinetic parameter values for simple reversible reaction used in TIPA Pathway. Table 4.2 shows the kinetic parameter values for enzymatic reaction used in TIPA Pathway.

TABLE 4.1: KINETIC VALUES FOR SIMPLE REVERSIBLE REACTION IN TIPA

\begin{tabular}{|c|c|c|}
\hline \multicolumn{3}{|c|}{ PATHWAY } \\
\hline Reaction & $\begin{array}{l}\text { Association } \\
\text { Constant }\left(\mathrm{K}_{\mathrm{a}}\right) \\
(\mathrm{mol} / \mathrm{sec})\end{array}$ & $\begin{array}{c}\text { Dissociation } \\
\text { Constant }\left(\mathrm{K}_{\mathrm{d}}\right) \\
(\mathrm{mol} / \mathrm{sec})\end{array}$ \\
\hline Thrombin $\leftrightarrow$ PAR-1[19] & $80\left(\mathrm{~K}_{\mathrm{a} 1}\right)$ & $107 * 10^{-6}\left(\mathrm{~K}_{\mathrm{d} 1}\right)$ \\
\hline Gq-GDP $\leftrightarrow$ Gq-GTP[20] & $1 * 10^{-6}\left(\mathrm{~K}_{\mathrm{a} 2}\right)$ & $4.2 * 10^{-6}\left(\mathrm{~K}_{\mathrm{d} 2}\right)$ \\
\hline Ras-GTP $\leftrightarrow$ Gq-GDP[21] & $0.0010\left(\mathrm{~K}_{\mathrm{a} 3}\right)$ & $0.0053 * 10^{-6}\left(\mathrm{~K}_{\mathrm{d} 3}\right.$ \\
\hline Raf $\leftrightarrow$ Ras-GTP[22] & $1000 * 10^{-6}\left(\mathrm{~K}_{\mathrm{a} 4}\right)$ & $1000\left(\mathrm{~K}_{\mathrm{d} 4}\right)$ \\
\hline$* \mathrm{IP} 3 \leftrightarrow \mathrm{Ca}[23]$ & $1.2^{*} 10^{8}\left(\mathrm{~K}_{\mathrm{a} 5}\right)$ & $2.2\left(\mathrm{~K}_{\mathrm{d} 5}\right)$ \\
\hline$* \mathrm{PKC} \leftrightarrow \mathrm{GP} 2 \mathrm{~b} 3 \mathrm{a}[24]$ & $1.2 * 10^{10}\left(\mathrm{~K}_{\mathrm{a} 6}\right)$ & $8.9\left(\mathrm{~K}_{\mathrm{d} 6}\right)$ \\
\hline$* \mathrm{DAG} \leftrightarrow \mathrm{PKC}[25]$ & $1 * 10^{-15}\left(\mathrm{~K}_{\mathrm{a} 7}\right)$ & $0.1\left(\mathrm{~K}_{\mathrm{d} 7}\right)$ \\
\hline *GP2b3a↔Fibrinogen[26] & $3.1 * 10^{5}\left(\mathrm{~K}_{\mathrm{a} 8}\right)$ & $5.1 * 10^{-2}\left(\mathrm{~K}_{\mathrm{d} 8}\right)$ \\
\hline
\end{tabular}

TABLE 4.2: KINETIC VALUES FOR ENZYMATIC REACTION IN TIPA PATHWAY

\begin{tabular}{|c|c|c|}
\multicolumn{4}{l}{ IN TIPA PATHWAY } \\
\hline Reaction & $\mathrm{V}_{\max }(\mathrm{mol})$ & $\mathrm{K}_{\mathrm{m}}(\mathrm{mol} / \mathrm{sec})$ \\
\hline $\mathrm{Raf} \rightarrow$ MEK $[27]$ & $50 * 10^{-6}\left(\mathrm{~V}_{\max 1}\right)$ & $9000\left(\mathrm{~K}_{\mathrm{m} 1}\right)$ \\
\hline $\mathrm{MEK} \rightarrow$ ERK $[21]$ & $8.3 * 10^{-6}\left(\mathrm{~V}_{\max 2}\right)$ & $9000\left(\mathrm{~K}_{\mathrm{m} 2}\right)$ \\
\hline$* \mathrm{PLC} \rightarrow$ PIP2[28] & $5.5 * 10^{-9}\left(\mathrm{~V}_{\max 3}\right)$ & $0.6\left(\mathrm{~K}_{\mathrm{m} 3}\right)$ \\
\hline$* \mathrm{PIP} 2 \rightarrow$ DAG[25] & $14\left(\mathrm{~V}_{\max 4}\right)$ & $97 * 10^{-6}\left(\mathrm{~K}_{\mathrm{m} 4}\right)$ \\
\hline$* \mathrm{PIP} 2 \rightarrow \mathrm{IP} 3[25]$ & $14\left(\mathrm{~V}_{\max 5}\right)$ & $97 * 10^{-6}\left(\mathrm{~K}_{\mathrm{m} 5}\right)$ \\
\hline
\end{tabular}

Note for Table 4.1 and 4.2: * indicates the reactions that are common to Collagen Induced Platelet Aggregation (CIPA) Pathway too.

\section{Differential Equations}

The Ordinary Differential Equations (ODE) used in the model is shown below.

Note for Section C :

[ ] indicates concentration of the metabolite.

* indicates the ODE that are common to CIPA Pathway.

$\mathrm{d}[$ Thrombin $] / \mathrm{dt}=\left([\mathrm{PAR}-1] * \mathrm{~K}_{\mathrm{d} 1}\right)-\left([\right.$ Thrombin $\left.] * \mathrm{~K}_{\mathrm{a} 1}\right)$ $\mathrm{d}[\mathrm{Gq}-\mathrm{GTP}] / \mathrm{dt}=\left([\mathrm{Gq}-\mathrm{GDP}] * \mathrm{~K}_{\mathrm{a} 2}\right)-([\mathrm{Gq}-\mathrm{GTP}] *$ $\left.\mathrm{K}_{\mathrm{a} 2}\right)-\left([\mathrm{Gq}-\mathrm{GTP}]^{*} \mathrm{~K}_{\mathrm{d} 2}\right)+$

$\mathrm{d}[\mathrm{PLC}-$ beta $] / \mathrm{dt}=0$. $\left([\mathrm{PLC}-\mathrm{Gq}-\mathrm{GTP}] * \mathrm{~K}_{\mathrm{d} 2}\right)$.

$\mathrm{d}[\mathrm{Gq}-\mathrm{GDP}] / \mathrm{dt}=[$ Ras-GTP $] * \mathrm{~K}_{\mathrm{a} 3}-[\mathrm{Gq}-\mathrm{GDP}] * \mathrm{~K}_{\mathrm{a} 2}-$ $[\mathrm{Gq}-\mathrm{GDP}] * \mathrm{~K}_{\mathrm{d} 3}+[\mathrm{Gq}-\mathrm{GTP}] * \mathrm{~K}_{\mathrm{d} 2}$

$\mathrm{d}[\mathrm{PAR}-1] / \mathrm{dt}=\left(\left[\right.\right.$ Thrombin] $\left.* \mathrm{~K}_{\mathrm{a} 1}\right)-\left([\mathrm{PAR}-1] * \mathrm{~K}_{\mathrm{d} 1}\right)$ $\mathrm{d}[$ Ras-GTP $] / \mathrm{dt}=\left([\mathrm{Gq}-\mathrm{GDP}] * \mathrm{~K}_{\mathrm{d} 3}\right)-([$ Ras-GTP $] *$ $\left.\mathrm{K}_{\mathrm{d} 4}\right)-\left([\mathrm{Ras}-\mathrm{GTP}] * \mathrm{~K}_{\mathrm{a} 3}\right)+([\mathrm{Raf} 1] *$

$\mathrm{d}[$ Galpha $] / \mathrm{dt}=0$ $\left.\mathrm{K}_{\mathrm{a} 3}\right)$

$\mathrm{d}[\mathrm{Raf}] / \mathrm{dt}=\left([\mathrm{Ras}-\mathrm{GTP}] * \mathrm{~K}_{\mathrm{d} 4}\right)-\left([\mathrm{Raf}] * \mathrm{~K}_{\mathrm{a} 3}\right)-(([\mathrm{Raf}] *$ $\left.\left.\mathrm{V}_{\max 1}\right) /\left([\mathrm{Raf}]+\mathrm{K}_{\mathrm{m} 1}\right)\right)$

$\mathrm{d}[\mathrm{MEK}] / \mathrm{dt}=\left(\left([\mathrm{Raf}] * \mathrm{~V}_{\max 1}\right) /\left([\mathrm{Raf}]+\mathrm{K}_{\mathrm{m} 1}\right)\right)-(([\mathrm{MEK}] *$ $\mathrm{d}[\mathrm{ERK} 2] / \mathrm{dt}=0$ $\left.\left.\mathrm{V}_{\max 2}\right) /\left([\mathrm{MEK}]+\mathrm{K}_{\mathrm{m} 2}\right)\right)$

$\mathrm{d}[\mathrm{ERK} 1] / \mathrm{dt}=\left(\left([\mathrm{MEK}] * \mathrm{~V}_{\max 2}\right) /\left([\mathrm{MEK}]+\mathrm{K}_{\mathrm{m} 1}\right)\right)$

$\mathrm{d}\left[\mathrm{ca} \_\mathrm{c} 1\right] / \mathrm{dt}=2 *\left[\mathrm{ca} \_\mathrm{c} 1\right] * 0.000144$

$\mathrm{d}[\mathrm{PLC}-\mathrm{Gq}-\mathrm{GTP}]=\left([\mathrm{Gq}-\mathrm{GTP}] * \mathrm{~K}_{\mathrm{a} 2}\right)-(([\mathrm{PLC}-\mathrm{Gq}-\mathrm{GTP}]$

$\left.\left.* \mathrm{~V}_{\max 3}\right) /\left([\mathrm{PLC}-\mathrm{Gq}-\mathrm{GTP}]+\mathrm{K}_{\mathrm{m} 3}\right)\right)$

$-\left([\mathrm{PLC}-\mathrm{Gq}-\mathrm{GTP}] * \mathrm{~K}_{\mathrm{d} 2}\right)$

$\mathrm{d}[\mathrm{PIP} 2] / \mathrm{dt}=\left(\left([\mathrm{PLC}-\mathrm{Gq}-\mathrm{GTP}] * \mathrm{~V}_{\max 3}\right) /([\mathrm{PLC}-\mathrm{Gq}-\mathrm{GTP}]\right.$ $\left.\left.+\mathrm{K}_{\mathrm{m} 3}\right)\right)-2 *\left(\left([\mathrm{PIP} 2] * \mathrm{~V}_{\max 4}\right) /([\mathrm{PIP} 2]+\right.$ $\left.\left.\mathrm{K}_{\mathrm{m} 4}\right)\right)$

$* \mathrm{~d}[\mathrm{DAG}] / \mathrm{dt}=\left(\left([\mathrm{PIP} 2] * \mathrm{~V}_{\max 4} /\left(\left([\mathrm{PIP} 2]+\mathrm{K}_{\mathrm{m} 4}\right)\right)-\right.\right.$ $\left([\mathrm{DAG}] * \mathrm{~K}_{\mathrm{a} 7}\right)+\left([\mathrm{PKC}] * \mathrm{~K}_{\mathrm{d} 7}\right)$

$* \mathrm{~d}[\mathrm{PKC}] / \mathrm{dt}=[\mathrm{DAG}] * \mathrm{~K}_{\mathrm{a} 7}-[\mathrm{PKC}] * \mathrm{~K}_{\mathrm{d} 7}-([\mathrm{PKC}] *$ $\left.\mathrm{K}_{\mathrm{a} 6}\right)+\left([\mathrm{GP} 2 \mathrm{~b} 3 \mathrm{a}] * \mathrm{~K}_{\mathrm{d} 6}\right)$

$* \mathrm{~d}[\mathrm{GP} 2 \mathrm{~b} 3 \mathrm{a}] / \mathrm{dt}=\left([\mathrm{Fib}] * \mathrm{~K}_{\mathrm{d} 8}\right)-\left([\mathrm{GP} 2 \mathrm{~b} 3 \mathrm{a}] * \mathrm{~K}_{\mathrm{a} 8}\right)+$ $\left([\mathrm{PKC}] * \mathrm{~K}_{\mathrm{a} 6}\right)-\left([\mathrm{GP} 2 \mathrm{~b} 3 \mathrm{a}] * \mathrm{~K}_{\mathrm{d} 6}\right)$

$* \mathrm{~d}[$ Fibrinogen $] / \mathrm{dt}=\left([\mathrm{GP} 2 \mathrm{~b} 3 \mathrm{a}] * \mathrm{~K}_{\mathrm{a} 8}\right)-\left([\mathrm{Fib}] * \mathrm{~K}_{\mathrm{d} 8}\right)$

$* \mathrm{~d}[\mathrm{IP} 3] / \mathrm{dt}=\left(\left([\mathrm{PIP} 2] * \mathrm{~V}_{\max 5}\right) /\left([\mathrm{PIP} 2]+\mathrm{K}_{\mathrm{m} 5}\right)\right)-([$ IP3] $*$ $\left.\mathrm{K}_{\mathrm{a} 5}\right)+\left(\right.$ [ca_ion] $\left.* \mathrm{~K}_{\mathrm{d} 5}\right)$

$* \mathrm{~d}[$ ca_ion $] / \mathrm{dt}=\left([\mathrm{IP} 3] * \mathrm{~K}_{\mathrm{a} 5}\right)-\left([\right.$ ca_ion $\left.] * \mathrm{~K}_{\mathrm{d} 5}\right)$

$\mathrm{d}\left[\mathrm{ca} \_\mathrm{c} 2\right] / \mathrm{dt}=-\left(\left[\mathrm{ca} \_\mathrm{c} 1\right] * 0.000144\right)$

\section{Collagen Induced Platelet Aggregation}

Platelet adhesion to sub-endothelium is the first reaction in the thrombus forming system of blood vessels. Collagen is one of the major components of the blood vessel wall. Collagen has been recognized as a key thrombogenic component of the vessel wall in particular types I, III, VI. Several collagen binding proteins include integrin $\alpha_{2} \beta_{1}$, GP $V I, G P I V$ and non-integrin $64 \mathrm{KD}$ protein specific for type I collagen. When vessel wall becomes damaged platelet adhere to and are activated on the exposed surface leading to thrombus formation.

Many glycoproteins on the platelet surface were reported to be putative collagen receptors but among them only two glycoprotein's have properties consistent with them being relative collagen receptors, one is GPVI and other is $\alpha_{2} \beta_{1}$ 
(GPIa/IIIa). Platelets deficient in these show loss of reactivity to collagen. It has been hypothesized that the high affinity interaction of platelets with collagen through integrin $\alpha_{2} \beta_{1}$ functions in platelet activation and lower affinity interaction between collagen and GPVI mainly serve to induce activation pathways in platelets. Contact of circulating platelets with exposed sub-endothelium results in release, generation or exposure of agonists which in turn can activate platelets in positive feedback loop. Among these agonist are Collagen (Exposed), Thrombin (Generated), ADP, Epinephrine and Serotonin (Released).

Agonist stimulated platelets change shape from spherical to discoid and subsequently aggregate, which requires activation of the platelet integrin adhesion receptor $\alpha_{\mathrm{IIb}} \beta_{3}$ to bind Fibrinogen and link adjacent platelet together in an aggregate. Phosphorylation process which is initiated by a $s r c$ family Kinase deactivates a signaling cascade resulting in Tyrosine phosphorylation and activation of $P L C$.

Platelet collagen interactions in vivo are likely to involve the integration of atleast two distinct receptors. Collagen interactions acting in concert: One involving $\alpha_{2} \beta_{1}$ as an adhesion/signaling receptor and other involving recognition of collagen structural features by receptor other than $\alpha_{2} \beta_{1}$, a likely one being GPVI which appears to play a major role in collagen induced platelet activation. Platelets play a critical role in events that lead to thrombus formation and cessation of bleeding at sites of damage to the vasculature. They play major role in thrombotic diseases such as stroke and myocardial infection.
At medium and high shear rates found in arterioles and damaged vascular beds $v W F$ bridges newly exposed collagen fibrils to $G P I b-I X-V$ complex on the platelet surface. This interaction is facilitated by fast on-rate of association between $v W F$ and GPIb $\alpha$ and is essential for initial tethering of platelets. The interaction is opposed off by a rapid off-rate of dissociation such that platelets role for several minutes on $v W F$ in the absence of other proteins before forming stable adhesion through activated $\alpha_{\mathrm{IIb}} \beta_{3}$. The inside out signals from GPVI promote $\alpha_{2} \beta_{1}$ activation and enable it to bind to collagen. GPVI is unable to mediate adhesion but, via activation of the $F c R \gamma$ (Fc Receptor $\gamma$-chain), induces intracellular signaling processes which promote the inside-out activation of integrins such as $\alpha_{I I b} \beta_{3}$ (GPIIb-IIIa) or $\alpha_{2} \beta_{1}$ (GPIa-IIa).

The interaction of activated integrins with the extracellular matrix assists in the adhesion of platelets to the injured vessel wall. During the next stage of platelet activation, a platelet plug forms through the recruitment of additional platelets from the circulation and their $\alpha_{I I b} \beta_{3^{-}}$mediated aggregation. The additional generation of platelets is mediated by a variety of other accumulating mediators that are produced or released once platelet adhesion has been initiated and some level of platelet activation through platelet adhesion receptors has occurred. These mediators include $A D P / A T P$ and Thromboxane A2 ( $T x A 2)$, which are secreted or released from activated platelets and thrombin, which is produced on the surface of activated platelets.

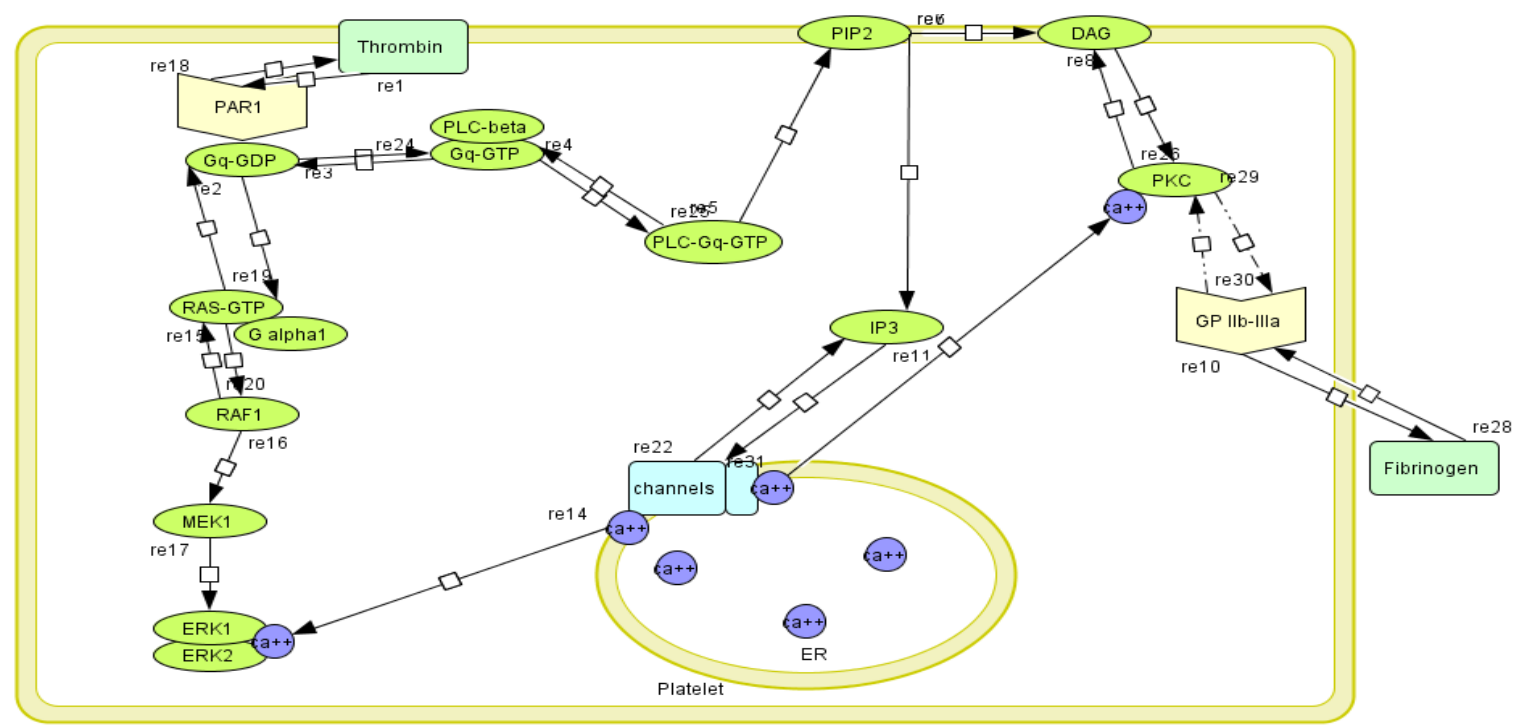

Fig. 4.1. TIPA Pathway Flux Map

The accumulation of platelets into a solid hemostatic thrombus is based on the formation of multiple platelets bound by fibrinogen. Platelet aggregation is mediated by integrin $\alpha_{I I b} \beta_{3}$, which binds various extracellular macromolecular ligands including fibrinogen and $v W F$. The dimeric structure of fibrinogen and the multimeric structure of $v W F$ allow these ligands to adhere with platelets, thereby clustering platelets to generate platelet aggregation. In inactivated, resting platelets, $\alpha_{I I b} \beta_{3}$ is in an off state, in which ligand binding affinities are low and no signaling occurs.

Platelet activation induces intracellular signaling processes that influence the cytoplasmic part of $\alpha_{I I b} \beta_{3}$, rapidly converting $\alpha_{I I b} \beta_{3}$ into an active conformation (inside-out signaling), which results in Fibrinogen $/ v W F$-mediated platelet aggregation. Platelet adhesion and aggregation are controlled by the activity of the platelet membrane receptors which biochemically are glycoproteins. The thrombus formation initiated by platelet adhesion to extracellular matrix (ECM) involves the synergistic function of at least four receptors, the $G P I b-I X-V$ complex and the integrins $\alpha_{2} \beta_{1}$ (GPIa-IIa), $\alpha_{I I b} \beta_{3}$ (GP IIb-IIIa) and $\alpha_{5} \beta_{1}$ (GPIc-IIIa). Aggregation, in contrast, may depend only on the $G P$ 
$I b-I X-V$ complex and $\alpha_{I I b} \beta_{3}$ (Fig. 5.1).

Typically, clot formation occurs only if the hemostatic stimulus reaches a certain threshold; this threshold is conditioned by both hemodynamic and biochemical factors including local flow conditions, availability of membrane binding sites for catalysis, concentration of di/multivalent ions like calcium $\left(\mathrm{Ca}^{2+}\right)$, and finally, concentrations of the reagents involved in clot formation: platelets and coagulation factors. Therefore, the hemostatic system can be thought of as a state of system idling due to subthreshold stimuli, which is primed to respond explosively once the threshold is crossed.

Activation of glycoprotein GPVI through its noncovalent association with the $F c R \gamma$ chain leads to the activation of the tyrosine kinase $S y k$, which regulates the function of $P L C \gamma 2$. Both activated $P L C \gamma 2$ and $P L C \beta 2 / 3$ generate the second messengers $D A G$ and $I P 3$, which promote activation of $P K C$ and increased cytosolic $\mathrm{Ca}^{2+}$ respectively.

\section{A. Pathway Description}

The flux map, created in CellDesigner 6.0.1, used in the simulation of Collagen Induced Platelet Aggregation (CIPA) pathway is shown in Fig.5.2. [15] [16] [17].

Collagen binding results in GPVI clustering and Tyrosine phosphorylation of the $F c R \gamma$ by the $S r c$-family kinases $L y n$ and Fyn. This result in the binding of the tyrosine Kinase Syk, which becomes Tyrosine Phosphorylated and activated. This leads to the Tyrosine Phosphorylation of the transmembrane adaptor protein Linker Activation of T-cells (LAT), which functions to assemble a complex of signaling proteins. Phosphoinositide 3 Kinase (PI3K) is recruited to LAT and, through the generation of, among other products, phosphatidylinositol (3, 4, 5)-trisphosphate [PIP3], influences the recruitment and activation of PhosphoLipase C $\gamma 2$ (PLC 2 2). PLC 2 cleaves PIP2 to generate IP3 and DAG. $I P 3$ and $D A G$ are responsible for the mobilization of calcium from intracellular stores and the activation of isoforms of $P K C$, respectively, both of which lead to secretion and aggregation.

Phosphoinositide metabolism was subsequently determined to be an important mechanism of platelet activation. Human platelets contain a Phosphoinositide-specific $P L C$ which, as a consequence of agonist-receptor binding, hydrolyzes $P I P 2$, a quantitatively minor membrane phospholipid, to the two potent stimulatory second messengers IP3 and DAG. Activation of platelet phosphoinositide-specific PLC results in the generation of $I P 3$ and $D A G$. These molecules affect divergent pathways of platelet activation: IP3 causes increase in cytoplasmic free calcium and $D A G$ causes activation of $P K C$. Each of these events, $\mathrm{Ca}^{2+}$ mobilization and $P K C$ activation, independently results in platelet activation; together they synergistically stimulate a diversity of platelet responses, including secretion and the release of arachidonic acid from membrane phospholipids stores.

\section{B. Kinetic Parameters}

TABLE 5.1: Kinetic VALUES FOR SimPLe REVERSible REACTIONS IN CIPA PATHWAY

\begin{tabular}{|c|c|c|}
\hline Reaction & $\begin{array}{c}\text { Association } \\
(\mathrm{mol} / \mathrm{sec}) \\
\text { Constant }\left(\mathrm{K}_{\mathrm{a}}\right)\end{array}$ & $\begin{array}{c}\text { Dissociation } \\
(\mathrm{mol} / \mathrm{sec}) \\
\text { Constant }\left(\mathrm{K}_{\mathrm{d}}\right)\end{array}$ \\
\hline $\begin{array}{c}\text { Collagen } \leftrightarrow \\
\text { GPVI[29] }\end{array}$ & $8.62 * 10^{3}\left(\mathrm{~K}_{\mathrm{a} 9}\right)$ & $5.04 * 10^{-3}\left(\mathrm{~K}_{\mathrm{d} 9}\right)$ \\
\hline Fcr $\leftrightarrow \leftrightarrow$ Syk[30] & $5.0 * 10^{-6}\left(\mathrm{~K}_{\mathrm{a} 10}\right)$ & $27.2^{2} 10^{-9}\left(\mathrm{~K}_{\mathrm{d} 10}\right)$ \\
\hline
\end{tabular}

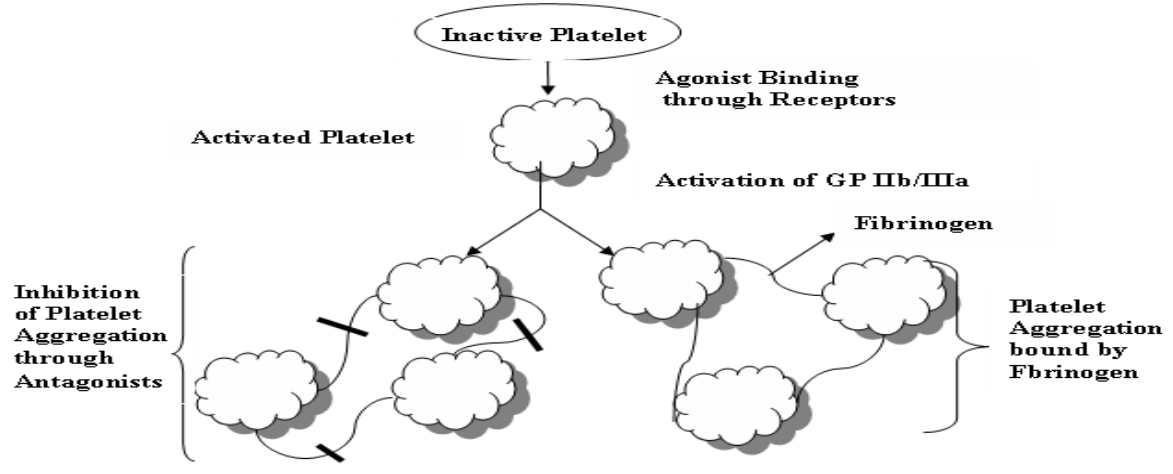

Fig. 5.1. Agonist Induced Platelet Aggregation and its Inhibition

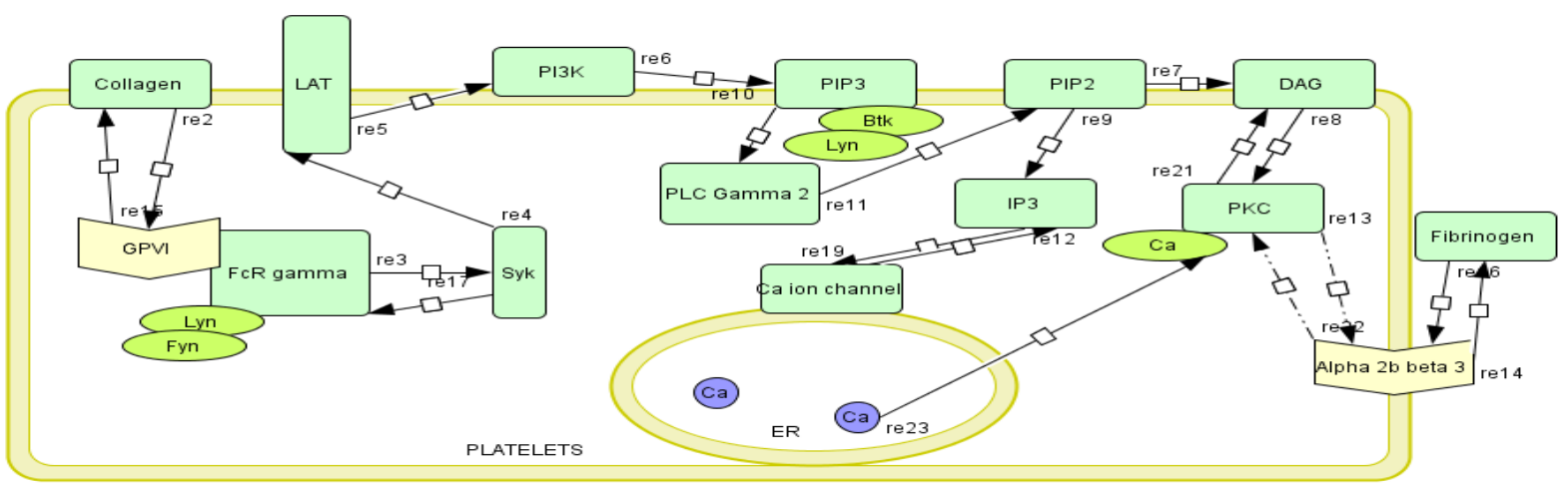

Fig. 5.2.CIPA Pathway Flux Map 
Table 5.1 shows the kinetic parameter values for enzymatic reaction used in CIPA Pathway. Table 5.2 shows the kinetic parameter values for enzymatic reaction used in CIPA Pathway.

TABLE 5.2 : KINETIC VALUES FOR ENZYMATIC REACTION IN CIPA

\begin{tabular}{|l|l|l|}
\hline Reaction & $\mathrm{V}_{\max }(\mathrm{mol})$ & $\mathrm{K}_{\mathrm{m}}(\mathrm{mol} / \mathrm{sec})$ \\
\hline Syk $\rightarrow$ LAT [31][11] & $2.8 * 10^{-9}($ & $1.0\left(\mathrm{~K}_{\mathrm{m} 6}\right)$ \\
& $\left.\mathrm{V}_{\max 6}\right)$ & \\
\hline PIP3 $\rightarrow$ PLC $\gamma 2$ & 2.8 & $1.0\left(\mathrm{~K}_{\mathrm{m} 7}\right)$ \\
{$[31][11]$} & $* 10^{-9}\left(\mathrm{~V}_{\max }\right)$ & \\
\hline LAT $\rightarrow$ PI3K & 40 & $3.7 * 10^{-6}\left(\mathrm{~K}_{\mathrm{m} 8}\right)$ \\
{$[31][11][32][33]$} & $* 10^{-9}\left(\mathrm{~V}_{\max 8}\right)$ & \\
\hline PI3K $\rightarrow$ PIP3 & $5.3\left(\mathrm{~V}_{\max 9}\right)$ & $17.5 * 10^{-3}\left(\mathrm{~K}_{\mathrm{m} 9}\right)$ \\
{$[31][11][32][33]$} & & \\
\hline
\end{tabular}

\section{A. Differential Equations}

The additional ordinary differential equations used in the model are shown below:

$\mathrm{d}[\mathrm{FCR}] / \mathrm{dt}=\left([\mathrm{syk}] * \mathrm{~K}_{\mathrm{d} 10}\right)-\left([\mathrm{FCR}] * \mathrm{~K}_{\mathrm{a} 10}\right)$

$\mathrm{d}[\mathrm{GP} 6] / \mathrm{dt}=\left([\right.$ Collagen $\left.] * \mathrm{~K}_{\mathrm{a} 9}\right)-\left([\mathrm{GP} 6] * \mathrm{~K}_{\mathrm{d} 9}\right)$

$\mathrm{d}[\mathrm{Lyn}] / \mathrm{dt}=0$

$\mathrm{d}[\mathrm{Fyn}] / \mathrm{dt}=0$

$\mathrm{d}[\mathrm{LAT}] / \mathrm{dt}=\left(\left([\mathrm{syk}] * \mathrm{~V}_{\max 6}\right) /\left([\mathrm{syk}]+\mathrm{K}_{\mathrm{m} 6}\right)\right)-(([\mathrm{LAT}] *$ $\left.\mathrm{V}_{\max 8} /\left([\mathrm{LAT}]+\mathrm{K}_{\mathrm{m} 8}\right)\right)$

$\mathrm{d}[\mathrm{syk}] / \mathrm{dt}=\left([\mathrm{FCR}] * \mathrm{~K}_{\mathrm{a} 10}\right)-\left(\left([\mathrm{syk}] * \mathrm{~V}_{\max 6}\right) /\right.$ $\left.\left([\mathrm{syk}]+\mathrm{K}_{\mathrm{m} 6}\right)\right)-\left([\mathrm{syk}] * \mathrm{~K}_{\mathrm{d} 10}\right)$

$\mathrm{d}[\mathrm{PI} 3 \mathrm{~K}] / \mathrm{dt}=\left(\left([\mathrm{LAT}] * \mathrm{~V}_{\max 8} /\left([\mathrm{LAT}]+\mathrm{K}_{\mathrm{m} 8}\right)\right)-\right.$ $\left(\left([\mathrm{PI} 3 \mathrm{~K}] * \mathrm{~V}_{\max 9}\right) /\left([\mathrm{PI} 3 \mathrm{~K}]+\mathrm{K}_{\mathrm{m} 9}\right)\right)$

$\mathrm{d}[\mathrm{PIP} 3] / \mathrm{dt}=\left(\left([\mathrm{PI} 3 \mathrm{~K}] * \mathrm{~V}_{\max 9}\right) /\left([\mathrm{PI} 3 \mathrm{~K}]+\mathrm{K}_{\mathrm{m} 9}\right)\right)-$ $\left(\left([\mathrm{PIP} 3] * \mathrm{~V}_{\max 7} /\left(\right.\right.\right.$ [PIP3] $\left.\left.+\mathrm{K}_{\mathrm{m} 7}\right)\right)$

$\mathrm{d}[\mathrm{PIP} 2] / \mathrm{dt}=\left(\left([\mathrm{PLC}] * \mathrm{~V}_{\max 3} /\left([\mathrm{PLC}]+\mathrm{K}_{\mathrm{m} 3}\right)\right)-2 *\right.$ $\left(\left([\mathrm{PIP} 2] * \mathrm{~V}_{\max 4}\right) /\left([\mathrm{PIP} 2]+\mathrm{K}_{\mathrm{m} 4}\right)\right)$

$\mathrm{d}[\mathrm{PLC}] / \mathrm{dt}=\left(\left([\mathrm{PIP} 3] * \mathrm{~V}_{\max 7} /\left([\mathrm{PIP} 3]+\mathrm{K}_{\mathrm{m} 7}\right)\right)-\right.$ $\left(\left([\mathrm{PLC}] * \mathrm{~V}_{\max 3} /\left([\mathrm{PLC}]+\mathrm{K}_{\mathrm{m} 3}\right)\right)\right.$

$\mathrm{d}\left[\mathrm{ca} \_\mathrm{c} 1\right] / \mathrm{dt}=\left[\mathrm{ca} \_\mathrm{c} 2\right] * 0.000144$

$\mathrm{d}[\mathrm{Btk}] / \mathrm{dt}=0$

$\mathrm{d}[$ Collagen $] / \mathrm{dt}=\left([\mathrm{GP} 6] * \mathrm{~K}_{\mathrm{d} 9}\right)-\left([\right.$ Collagen $\left.] * \mathrm{~K}_{\mathrm{a} 9}\right)$

$\mathrm{d}\left[\mathrm{ca} \_\mathrm{c} 2\right] / \mathrm{dt}=-($ [ca_c2] $* 0.000144)$

\section{PERformance ANALysis}

Simulations of both TIPA and CIPA Pathways were executed using CellDesigner. Fig. 6.1 shows the simulation results of TIPA Pathway. It is found that the sensitive parameters are IP3, PIP2, PKC, DAG and RAS-GTP. We observe that $P I P 2$ concentration is 25 moles, but it rapidly declines to 0 within a short period of time 0.9 second. It also shows the $D A G$ Concentration increases from 10 moles to 22 moles very rapidly and the curve becomes steady at $(0.9,22)$. The optimal concentrations of the above mentioned substrates have to be maintained for the efficiency of TIPA pathway. Fig. 6.2 shows the final simulation result of Collagen Induced Platelet Aggregation. It is found that the sensitive parameters are $P K C, P I P 3, P I P 2, P I 3 K, D A G$ and $I P 3$. We observe that $P I 3 K$ concentration is 5 moles, but it rapidly declines to 0 within short period of time 0.95 second. It also shows the PIP3 Concentration increases from 10 moles to 15 moles very rapidly and the curve becomes steady at $(0.95,15)$. The optimal concentrations of the above mentioned substrates have to be maintained for the efficiency of TIPA pathway.
These parameters $P I P 2, D A G, I P 3$ and $P K C$ are found sensitive because these proteins are responsible for activating the receptor GP IIb/IIIa, which in turn either aggregates the platelet (bound by fibrinogen) or inhibits the same through antagonists depending on the stimuli it gets.

\section{CONCLUSIONS}

Controlling Platelet Aggregation is essential for cardiac patients in dealing with strokes and other myocardial infarctions. Thrombin and Collagen are the agonists involved in the aggregation of platelets. We have used Kinetic Modeling on CellDesigner to find out the metabolites that should be targeted for antiplatelet drugs. It is found that the proteins PIP2, PIP3, PI3K, DAG, IP3 and $P K C$ are critical and they could be further used as novel putative drug targets for the new generation of antiplatelet drugs. Further, Homology Modeling can be used to design antiplatelet drug in future.

\section{REFERENCES}

[1] H Kaheno, "Foundations of Systems Biology" MIT Press [ISBN 0 262 -11266-0], 2001.

[2] http://www.systems-biology.org.

[3] Athel Cornish-Bowden, "Foundations of Enzyme Kinetics," ( $3^{\text {rd }}$ Edition), Portland Press [ISBN 1-85578-156-1], 2004.

[4] S. Offermanns, " Activation of Platelet Function through G Protein Coupled Receptors," Circ. Res., vol. 99, pp.1293-1304, 2006.

[5] Harmon J.T and G.A. Jamieson, “ The Glycoalicin Portion of Platelet Glycoprotein Ib Expresses Both High and Moderate Affinity Receptor Sites for Thrombin. A Soluble Radioreceptor Assay for the Interaction of Thrombin with Platelets," Journal of Biological Chemistry, vol. 261, pp. 13224-13229, 1986.

[6] RamakrishnaV, DeGuzman, M Bao , S.W. Hall , L.L. Leung and D.R.Phillips, "Thrombin Receptor Function for Platelet Glycoprotein Ib- IX Unmasked by Cleavage of Glycoprotein V," Proc. Natl. Acad. Sci. USA, vol. 98, pp. 1823-1828, 2001.

[7] Fukuhara S., C.Murga, M.Zohar, T.Igishi and J.S.Gutkind , “ A Novel PDZ Domain Containing Guanine Nucleotide Exchange Factor Links Heterotrimeric G Proteins to Rho," Journal of Biological Chemistry, vol. 274, pp. 5868-5879, 1999.

[8] Suzanne L. Jacques, Meredith Lemasurier, Paul J. Sheridan, Stacy K.Seeley and Athan Kuliopulos, "Substrate-Assisted Catalysis of the PAR1 Thrombin Receptor," Journal of Biological Chemistry, vol. 275, pp.40671-40678, 2000.

[9] Zhang J, W.J.King, S.Dillon ,A.Hall ,L. Feig and S.E.Rittenhouse, "Activation of Platelet Phosphatidylinositide 3-Kinase Requires the Small GTP-binding Protein Rho," Journal of Biological Chemistry, vol. 268, pp.22251-22254, 1993.

[10] Masaaki Moroi, Stephanie M.Jung, Shosaku Nomura ,Sadayoshi Sekiguchi, Antonio Ordinas and Maribel Diaz-Ricart, "Analysis of the Involvement of the von Willebrand Factor-Glycoprotein Ib Interaction in platelet Adhesion to a Collagen-Coated Surface UnderFlow Conditions," Blood, vol.90, pp.4413-4424,2008.

[11] Jean-Max Pasquet, Barbara Gross, Lynn Quek, Naoki Asazuma, Weiguo Zhang, Connie L. Sommers, Edina Schweighoffer, Victor Tybulewicz, Barbara Judd, Jong Ran Lee, Gary Koretzky, Paul E. Love, Lawrence E. Samelson and Steve P. Watson," LAT is required for Tyrosine Phosphorylation of Phospholipase C- $\gamma 2$ and Platelet Activation by the Collagen Receptor GPVI, " Journal of Molecular and Cellular Biology, vol.19, pp. 8326-8334, 1999.

[12] Monroe, Hoffman and Robert, "Platelets and Thrombin Generation" Arterioscler Thromb Vasc Biol, vol. 22, pp. 1381-1389, 2002.

[13] Shapiro M.J., E.j. Weiss, T.R. Faruqi and S.R. Coughlin, "Protease Activated Receptors 1 and 4 are Shut off with Distinct Kinetics after Activation by Thrombin," Journal of Biological N-terminal ERK-binding Site of MEK1 is Required for Efficient Chemistry, vol.275,pp.25216-25221,2000. 
[14] Scott, R.Macfarlane, Michel J. Seatter, Torukanke, Gary D. Hunter and Robin Plevin, "Proteinase - Activated Receptors,"Journal of Pharmacology, vol. 53, pp. 245-282, 2001.

[15] http://www6. ufrgs.br /favet/imunovet/ molecular_ Immunology / Thrombosis. jpg.

[16] http://www.patient.co.uk/images/OM1028a.jpg.

[17] http://www.chelationtherapyonline.com/ arryGordon /images/ p9.htm1.gif

[18] Gerald Soslau, Reiner Class, Doris A. Morgan, Carolyn Foster, Susan T. lord, Patrizia Marchese and Zaverio M. Ruggeri, "Unique Pathway of Thrombin-induced Platelet Aggregation Mediated by Glycoprotein Ib," Journal of Biological Chemistry, vol.276, pp.21173-21183, 2001

[19] Marina A. Parry, Timothy Myles, Jurg Tschopp and Stuart R. Stone, "Cleavage of the Thrombin Receptor: Identification Of Potential Activators and Inactivators," Journal of Biological Chemistry, pp. 335-341, 1996.Chemistry, vol.267, pp. 16044- 16047, 1992. Chang Ho Lee, Dongeun Park, Dianqing Wu, Sue Goo Rheeg and Melvin I. Simon, "Members of the $G q$ alpha Subunit Gene Family Activate PLC-beta Isozymes," Journal of Biological Chemistry, vol. 267, pp. 16044-16047, 1992.

[20] David Tulasnel, Teresa Bori and Steve Watson, "Regulation of RAS in Human Platelets Evidence that Activation of RAS is not sufficient to lead to ERK1-2 Phosphorylation," Journal of Biological Chemistry, vol. 269, pp. 1511-1517, 2002.

[21] Akio Maeda, Yu-ichi Ozaki, Sudhir Sivakumaran, Tetsuro Akiyama, Hidetoshi, Urakubo, Ayako Usami, Miharu Sato, Kozo Kaibuchi and Shinya Kuroda, "Ca2 ${ }^{+}$-Independent Phospholipase A2-Dependent Sustained Rho-kinase Activation all-or-none response," Genes to Cells, 2006.

[22] Tobias Meyer, Theodore Wense and Lubert Stryer, "Kinetics of Calcium Channel Opening by Inositol 1, 4, 5-Trisphosphate," Journal of Biological Chemistry, vol. 29, pp. 32-37, 1990.
[23] Eric A. Nalefski and Alexandra C. Newton, "Membrane Binding Kinetics of Protein Kinase C $\beta$ II Mediated by the C2 Domain," Journal of Biological Chemistry, vol. 40, pp. 13216-13229, 2001.

[24] http://www.ncbs.res.in/ bhalla/Itploop/constants.html.

[25] Walter Huber, Jiirg Hurst, Daniel Schlatter, Richard Barner, Josef Hubscher, William C. Kouns and Beat Steiner, "Determination of Kinetic Constants for the Interaction between the Platelet Glycoprotein IIb-IIIa and Fibrinogen by Means of Surface Plasmon Resonance," Journal of Biological Chemistry, pp. 647-656, 1995. Bing-E Xu, L. Julie. Wilsbacher, Tandi Collisson and Melanie H.Cobb, “The

[26] Feedback Phosphorylation by ERK2 In vitro and ERK Activation in vivo, "Journal of Biological Chemistry, vol. 274, pp. 34029-34035, 1999.

[27] Matthew Wahi, Gwenith A. Jones, Shunzo Nishibe, Sue Goo Rhee and Graham Carpenter, "Growth Factor Stimulation of Phospholipase C- $\gamma 1$ Activity," Journal of Biological Chemistry, vol. 267, pp. 10447-10556, 1992.

[28] Yoshiki Miura, Tsuyoshi Takahashi, Stephanie M. Jung and Masaaki Moroi, "Analysis of the Interaction of Platelet Collagen Receptor Glycoprotein VI with Collagen," Journal of Biological Chemistry, vol. 277, pp. 46197-46207, 2002

[29] Jla-ying Butt, Andrey S.Shaw and Andrew C.Chan, "Analysis of the Interaction of ZAP-70 and Syk Protein-Kinases with the T-cell Antigen Receptor by Plasmon Resonance, " Proc. Natl.Acad.Sci., USA, vol. 92 , pp. 5106 - 5110, 1995.

[30] Gwenith A. Jones and Graham Carpenter, "The Regulation of Phospholipase C- $\gamma 1$ by Phosphatidic Acid," Journal of Biological Chemistry, vol. 268, pp. 20845-20850, 1993.

[31] T M Pawlik, W W Souba and B P Bode, "Asparagine Uptake in Rat Hepatocytes: Resolution of a Paradox and Insights into Substrate-Dependent Transporter Regulation," Amino Acids, vol. 20, pp.335-352, 2001.

[32] Kong D and Yamori T, "ZSTK474 is an ATP-Competitive Inhibitor of class I Phosphatidylinositol 3 Kinase Isoforms," Cancer Sci., vol. 10, pp. 1638-1642, 2007 